\title{
Influence of Applied Bias Voltage on the Composition, Structure, and Properties of Ti:Si-Codoped a-C:H Films Prepared by Magnetron Sputtering
}

\author{
Jinlong Jiang, ${ }^{1,2}$ Qiong Wang, ${ }^{1}$ Yubao Wang, ${ }^{1}$ Zhang Xia, ${ }^{1}$ Hua Yang, and Junying Hao ${ }^{2}$ \\ ${ }^{1}$ Department of Physics, Lanzhou University of Technology, Lanzhou 730050, China \\ ${ }^{2}$ State Key Laboratory of Solid Lubrication, Lanzhou Institute of Chemical Physics, Chinese Academy of Sciences, \\ Lanzhou 730000, China
}

Correspondence should be addressed to Jinlong Jiang; jinlong@lut.cn

Received 9 December 2013; Accepted 14 January 2014; Published 3 March 2014

Academic Editor: Jun Yang

Copyright @ 2014 Jinlong Jiang et al. This is an open access article distributed under the Creative Commons Attribution License, which permits unrestricted use, distribution, and reproduction in any medium, provided the original work is properly cited.

\begin{abstract}
The titanium- and silicon-codoped a-C:H films were prepared at different applied bias voltage by magnetron sputtering TiSi target in argon and methane mixture atmosphere. The influence of the applied bias voltage on the composition, surface morphology, structure, and mechanical properties of the films was investigated by XPS, AFM, Raman, FTIR spectroscopy, and nanoindenter. The tribological properties of the films were characterized on an UMT-2MT tribometer. The results demonstrated that the film became smoother and denser with increasing the applied bias voltage up to $-200 \mathrm{~V}$, whereas surface roughness increased due to the enhancement of ion bombardment as the applied bias voltage further increased. The $\mathrm{sp}^{3}$ carbon fraction in the films monotonously decreased with increasing the applied bias voltage. The film exhibited moderate hardness and the superior tribological properties at the applied bias voltage of $-100 \mathrm{~V}$. The tribological behaviors are correlated to the $\mathrm{H} / \mathrm{E}$ or $\mathrm{H}^{3} / \mathrm{E}^{2}$ ratio of the films.
\end{abstract}

\section{Introduction}

The hydrogenated carbon film (a-C:H) has many unique mechanical, physical, and chemical properties such as high hardness, low friction coefficient, and high chemical inertness. These films have been widely used in many fields such as cylinder bores, engine piston rings, bearings, cutting tools and drills as solid lubricant, wear resistance, and hard protective coatings $[1,2]$. However, some intrinsic drawbacks, such as high internal stress, poor adhesion to substrates, low toughness, and high frictional sensitivity to the environments, considerably restrict their engineering applications $[3,4]$. Doping some metal and nonmetal elements is a simple and effective method to overcome the above problems. In recent years, some studies have reported the dual elements codoping of strong-carbide-forming metal such as $\mathrm{Ti}, \mathrm{W}$, or $\mathrm{Cr}$ and weak-carbide-forming metal such as $\mathrm{Al}, \mathrm{Cu}$ into the carbon matrix, which would form novel nanocomposite, solid solution, or self-organized nanostructures [5-7]; thus the films exhibit excellent mechanical and tribological properties.

In previous studies, we have demonstrated that the $\mathrm{sp}^{3}$ and $\mathrm{sp}^{2}$ ratio of the a-C:H films can be tuned by the codoping of $\mathrm{Ti}$ or $\mathrm{Al}$ and $\mathrm{Si}[8,9]$. Also, it was found that the synergistic action of dual elements can contribute to obtain the high hardness, high elasticity, and ultralow friction in the high vacuum and air environments $[7,10]$. In this paper, the $\mathrm{Ti}$ : $\mathrm{Si}$ codoped a-C:H films were prepared by middle-frequency magnetron sputtering TiSi target in argon and methane mixture atmosphere. Influence of applied bias voltage on the composition, structure, surface morphology, and properties of the films has been investigated.

\section{Experimental Details}

2.1. Film Preparation. The Ti:Si-codoped a-C:H films were prepared on $\mathrm{Si}$ (100) substrates by magnetron sputtering Ti80Si20 target in argon and methane mixed atmosphere. 


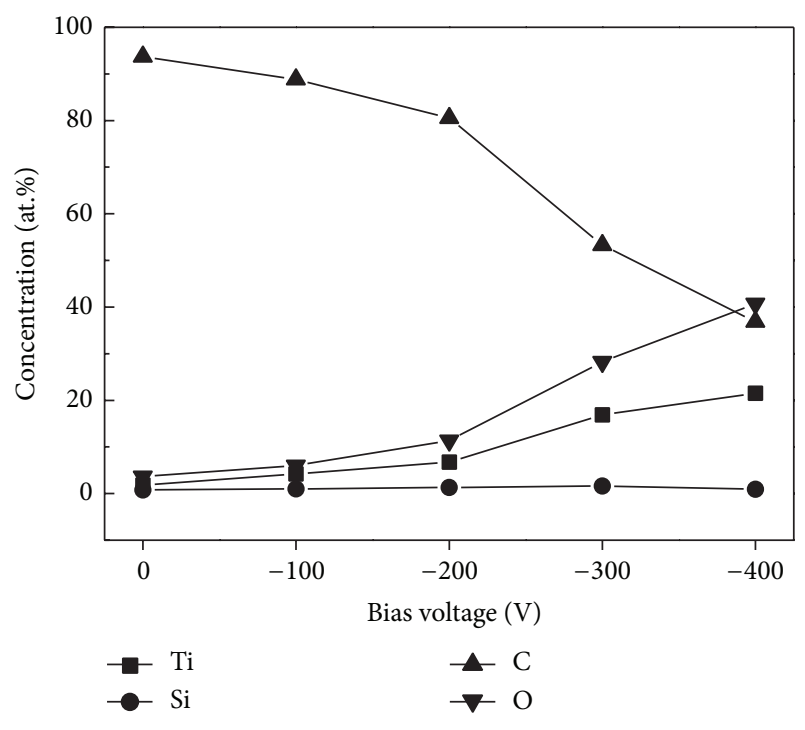

FIGURE 1: Variation of the concentration of titanium, silicon, carbon, and oxygen as a function of the applied bias voltage.

Prior to deposition, the Si substrates were ultrasonically cleaned in alcohol and acetone in succession and dried with a hot air. When the vacuum chamber was evacuated to a base pressure of $3.0 \times 10^{-3} \mathrm{~Pa}$, the argon gas was introduced into the chamber to $0.7 \mathrm{~Pa}$. The $\mathrm{Si}$ substrate was cleaned by $\mathrm{Ar}$ ion sputtering to clean oxide layer and adhering impurities. Subsequently, the films were prepared under $120 \mathrm{sccm}$ Ar and $40 \mathrm{sccm} \mathrm{CH}$ gas flow rate. The deposition pressure in the chamber was about $0.58 \mathrm{~Pa}$. During the film deposition process, the medium frequency $(20 \mathrm{kHz})$ magnetron sputtering target was kept at constant current of $2.2 \mathrm{~A}$. The substrate bias voltage varied from 0 to $-400 \mathrm{~V}$ with $80 \%$ duty factor. The distance between substrate and target was about $10 \mathrm{~cm}$. In the deposition process, the substrate was rotary at a speed of $12 \mathrm{rpm}$. No external heating was applied on the substrates.

2.2. Film Characterization. The surface morphology and surface roughness of the films were observed on an atomic force microscope (Nano IIIa AFM). Raman spectra were recorded by a Horiba Jobin Yvon HR800 Raman spectrometer with $532 \mathrm{~nm}$ Ar ion laser as the excitation resource. Fourier transform infrared spectra (FTIR) of the films were obtained on Nicolet Nexus 870 spectrometer with air as the background.

The hardness and elastic modulus of the films were detected on a nanoindenter (Nano Indenter II, MTS Systems Corporation) with a Berkovich diamond tip. The maximum indentation depth was kept at $70 \mathrm{~nm}$ to minimize the substrate contribution. The tribological behaviors of films were tested using a reciprocating UMT-2MT tribometer (Center for Tribology, Inc., CA, USA) at a load of $2 \mathrm{~N}$ and a sliding speed of $10 \mathrm{~cm} \mathrm{~s}^{-1}$ against a GCr 15 steel ball $(\phi=3 \mathrm{~mm}$, HRC $=64$, and $\mathrm{Ra}=0.02 \mu \mathrm{m})$. All tests were performed at room temperature with a relative humidity of $30-40 \%$.

\section{Results and Discussion}

3.1. Composition and Surface Morphology. Figure 1 shows the chemical composition of the films as a function of the applied bias voltage. It can be found that the $\mathrm{C}$ content quickly decreases from 93.7 at.\% to 36.9 at.\% with the increasing of the applied bias voltage, whereas $\mathrm{Ti}$ and $\mathrm{O}$ contents gradually increase from 1.8 at.\% and 0.82 at.\% to 21.5 at. $\%$ and 36.8 at.\%, respectively. The $\mathrm{Si}$ content is irregular in the range of $0.8-$ 1.6 at.\% at different applied bias voltage. As the applied bias voltage increased, the sputtering and etching of ions or atoms to the growing surface were stronger. The weakly bonded C adatoms would be more easily resputtered by incident highenergy ions in the growth process of the films, which lead to the decrease in $\mathrm{C}$ content and the increase in $\mathrm{Ti}$ content $[11,12]$.

Figure 2 shows the AFM surface morphologies of the films. It is seen from the 3D images that the surface morphologies of the films were strongly dependent on the applied bias voltage. At the low bias voltage of $0 \mathrm{~V}$, the film was composed of the uniform particles with sizes of several tens to one hundred of nanometers. Apparently, at higher bias voltage $(>-200 \mathrm{~V})$, the film became flatter, smoother, and denser. On the one hand, both plasma density and ion energy increased with increasing of the applied bias voltage; the etching effects became stronger and resulted in a finer and denser microstructure [13], since protrusions in the surface are usually resputtered preferentially. Therefore, it can be clearly seen that the root mean square (Rms) roughness decreased from about 4.2 to $0.7 \mathrm{~nm}$ with the increasing bias voltage from 0 to $-200 \mathrm{~V}$, as shown in Figure 3. On the other hand, at high bias voltage, bombardment of ions or radicals caused heating effect of the substrate and hence promoted the mobility and diffusion of species [14], which lead to an increase in surface roughness as the applied bias voltage further increased. Therefore, the variation trend of surface morphology is the result of the competition of the above two factors.

3.2. Structure. Raman spectroscopy is widely used to probe the detailed bonding structure of carbon films due to its ability to distinguish different bonding types, domain size, hydrogen content, and even sensitivity to internal stress [1517]. Figure 4 shows the Raman spectra of the films deposited at different substrate bias voltages, where the spectra have similar profiles. It is observed that the characteristic peaks in Raman spectra are overshadowed by photoluminescence background at the $0 \mathrm{~V}$ bias voltage, which is attributed to the hydrogen saturation of nonradiative recombination centers due to highly hydrogen content in the film [18]. As the applied bias voltage increased, a broad peak was observed at a range between 1000 and $1800 \mathrm{~cm}^{-1}$ for all the films, indicating typical features of the a-C:H films.

The Raman spectra were fitted with two Gaussian peaks that were denoted as a main $G$ peak at $1500-1600 \mathrm{~cm}^{-1}$ and a broad shoulder D peak at $1350-1370 \mathrm{~cm}^{-1}$. From the fitting results of the Raman spectra in Figure 5, it can be identified that the $G$ peak position shifted towards higher wavenumber 


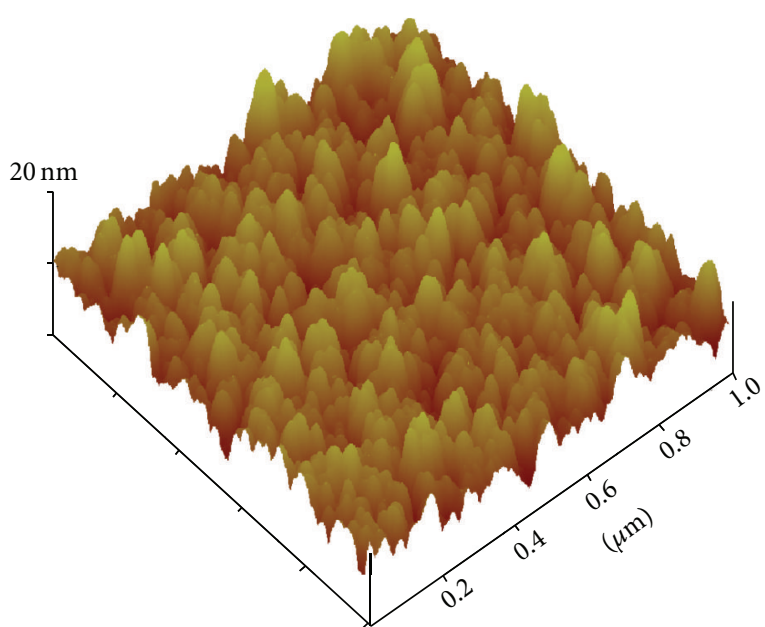

(a)

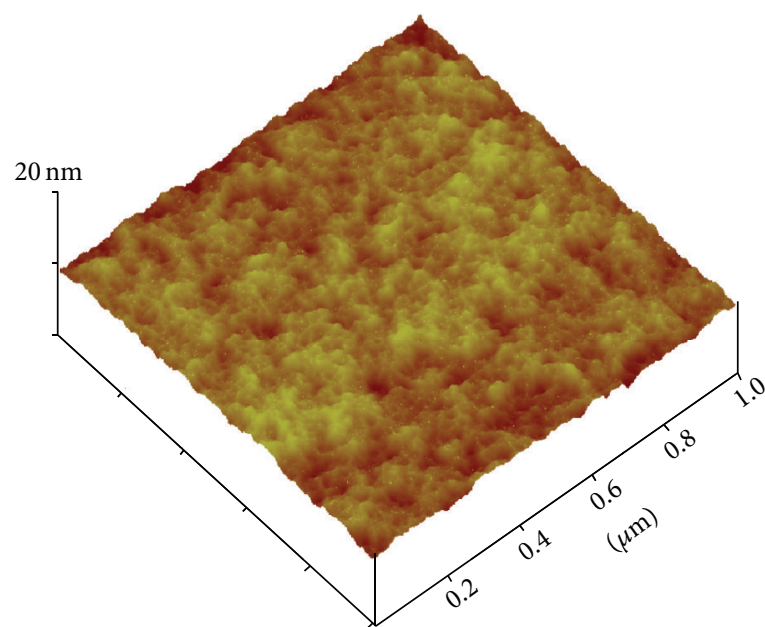

(b)

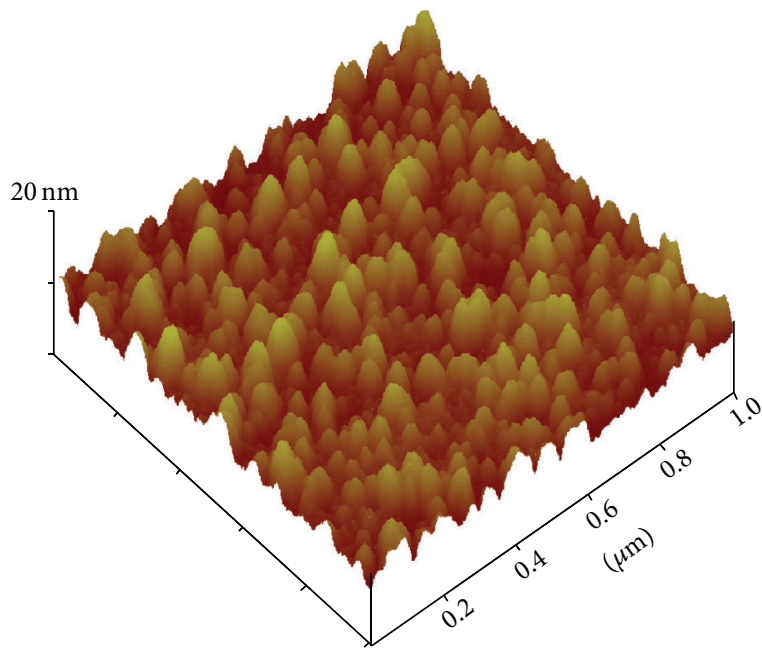

(c)

Figure 2: AFM surface morphology of the films at different applied bias voltage: (a) $0 \mathrm{~V}$; (b) $-200 \mathrm{~V}$; (c) $-300 \mathrm{~V}$.

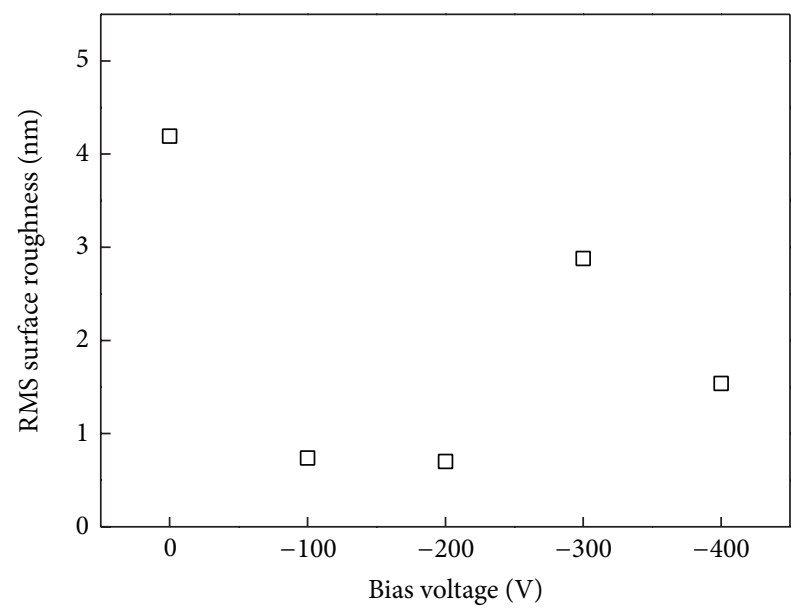

FIgURE 3: The Rms roughness of the film as a function of the applied bias voltage. from 1552 to $1572 \mathrm{~cm}^{-1}$ and the ratio of $\mathrm{I}(\mathrm{D}) / \mathrm{I}(\mathrm{G})$ increased from 0.74 to 1.32 , when the applied bias voltage increased from -100 to $-400 \mathrm{~V}$. This suggests that there is a gradual decrease in the $\mathrm{sp}^{3}$ hybridized carbon fraction. This variation trend can be explained from the growth progress of a-C:H film that primarily depended on ion energy controlled by the applied bias voltage. Accordingly, without the bias voltage applied to substrate, the prepared film has a higher C$\mathrm{H}$ bonding content due to especially low ion energy. It is known that ion bombardment can cause the displacement of $\mathrm{H}$ from $\mathrm{C}-\mathrm{H}$ bonds by forming $\mathrm{H}_{2}$ molecules [19]. As the applied bias voltage increased, $\mathrm{C}-\mathrm{H}$ bonds with $\mathrm{sp}^{3} \mathrm{C}-\mathrm{H}$ forms decreased in the films owing to the enhancement of ion bombardment. This result is confirmed from FTIR spectra in Figure 6. Although ion implantation could also give rise to the increase of $\mathrm{sp}^{3} \mathrm{C}-\mathrm{C}$ bonds as the bias voltage is generally applied in the range from about 0 to $-100 \mathrm{~V}$, the variation of $\mathrm{sp}^{3}$ carbon $(\mathrm{C}-\mathrm{C}, \mathrm{C}-\mathrm{H})$ fraction was dominated by the 


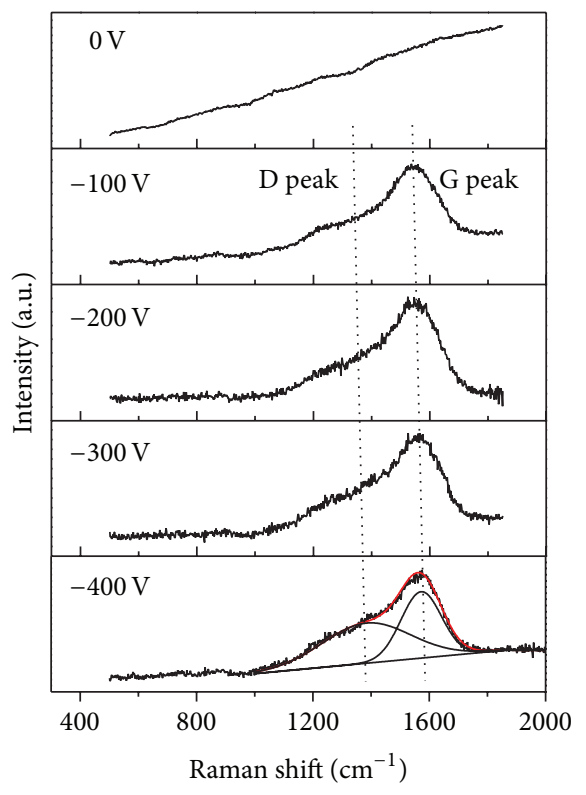

FIGURE 4: The Raman spectra of the films prepared at different applied bias voltage.

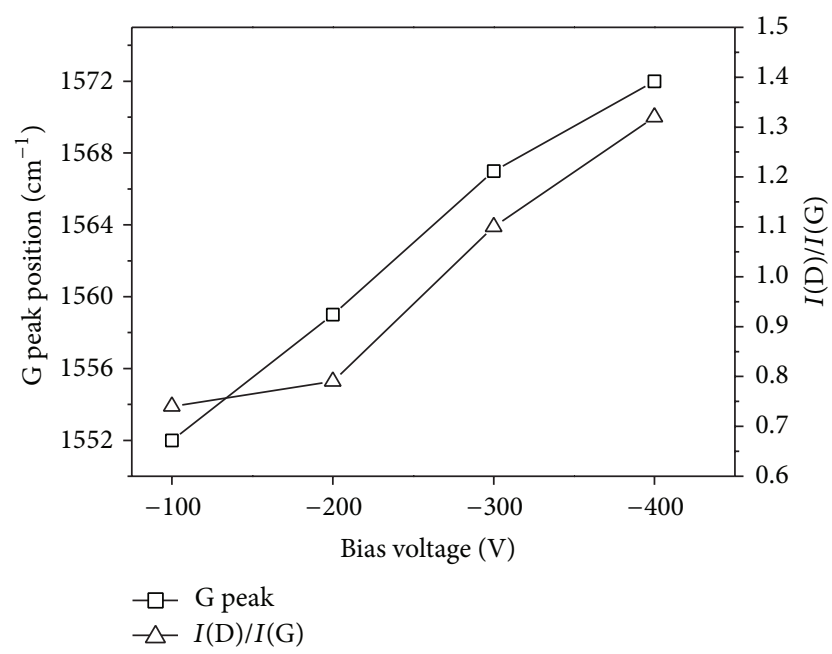

Figure 5: G peak position and $\mathrm{I}(\mathrm{D}) / \mathrm{I}(\mathrm{G})$ ratio of Raman spectra as a function of the applied bias voltage.

dehydrogenation process. Thus, $\mathrm{sp}^{3}$ carbon fraction in the films declined monotonically with increasing the applied bias voltage, as reported in [20,21].

The $\mathrm{C}-\mathrm{H}$ bonding states were characterized in the range of $2500-3400 \mathrm{~cm}^{-1}$ by FTIR spectroscopy. The broad absorption peaks centered at $2925 \mathrm{~cm}^{-1}$ with two smaller shoulder peaks corresponding to $\mathrm{sp}^{3} \mathrm{C}-\mathrm{H}_{x}$ stretching modes [22]. It can be obviously seen that the $\mathrm{C}-\mathrm{H}$ peak intensity decreased as the bias voltage increased. This suggests that the film prepared at high bias voltage has a low hydrogen content, which could be attributed to an enhanced bombardment by ion species with higher energy at higher bias voltage. From the results of Raman and FTIR, it is revealed that the

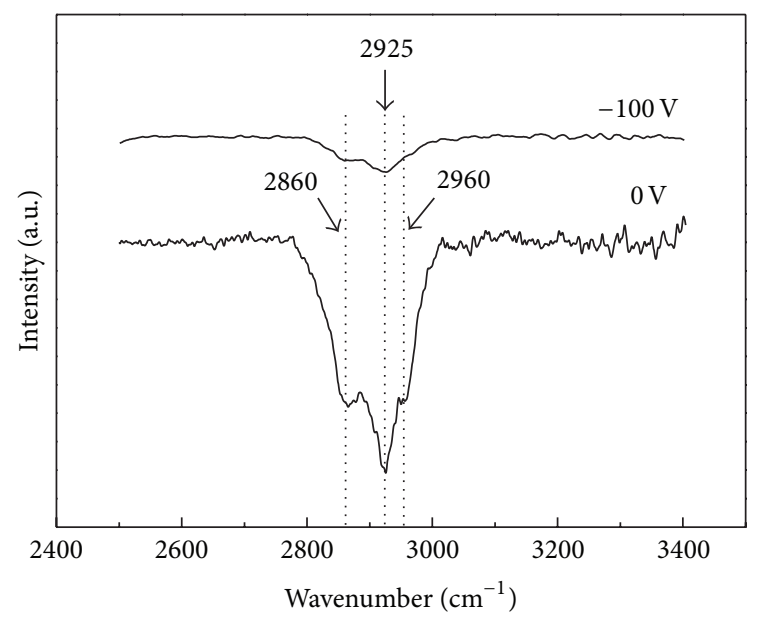

FIGURE 6: FTIR spectra of the films prepared at different applied bias voltage.

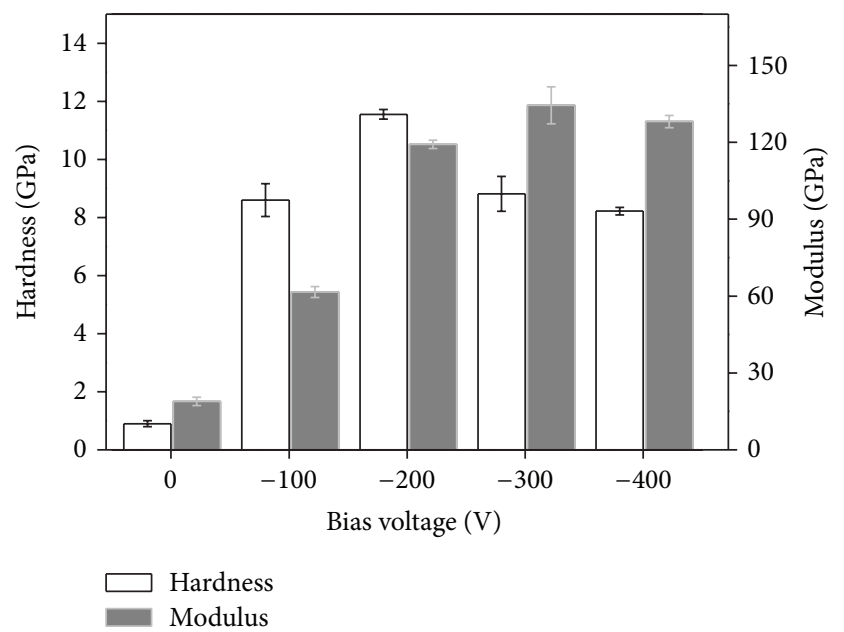

FIGURE 7: Variation of hardness and elastic modulus for the films prepared at different applied bias voltage.

applied bias voltage to substrate plays a major role in the microstructure of the a-C:H films.

3.3. Mechanical and Tribological Properties. The hardness and elastic modulus values of the films prepared at different applied bias voltage are shown in Figure 7. It is seen that the film deposited without applied bias voltage is relatively soft with a hardness of $0.9 \mathrm{GPa}$, which is probably due to nature of polymer-like structure caused by considerably high bondedhydrogen content in the film. The hardness increased to a maximum value of $11.6 \mathrm{GPa}$ with increasing the applied bias voltage to $-200 \mathrm{~V}$ and then decreased with further increasing of the applied bias voltage. With increase of the applied bias voltage, it was believed that more $\mathrm{sp}^{3} \mathrm{C}-\mathrm{C}$ can be formed due to the ion subplantation and would contribute to the increase of the hardness. Furthermore, the density of the films increased as the applied bias voltage increased, which might be the other important factor contributing to the 


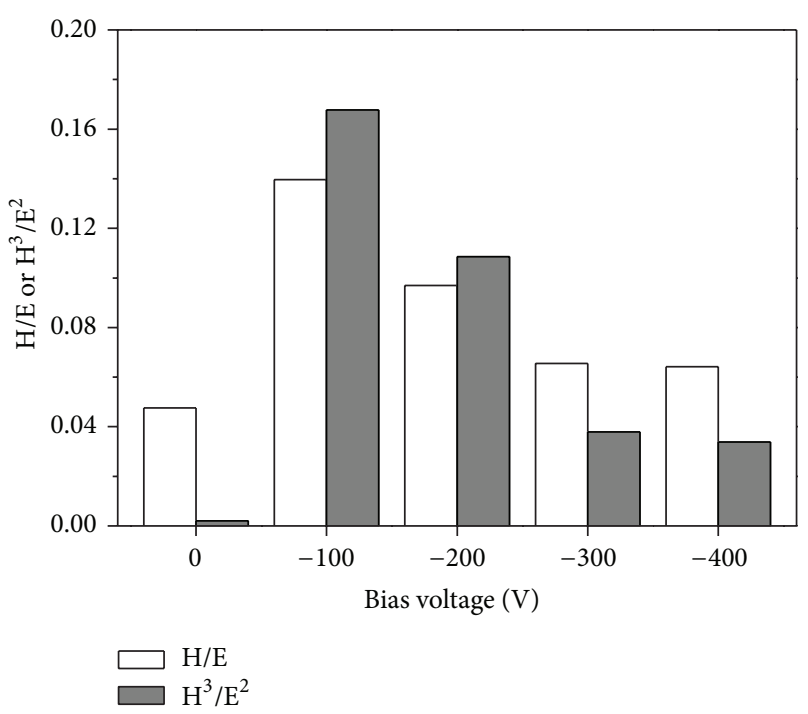

Figure 8: Variation of $\mathrm{H} / \mathrm{E}$ and $\mathrm{H}^{3} / \mathrm{E}^{2}$ for the films prepared at different applied bias voltage.

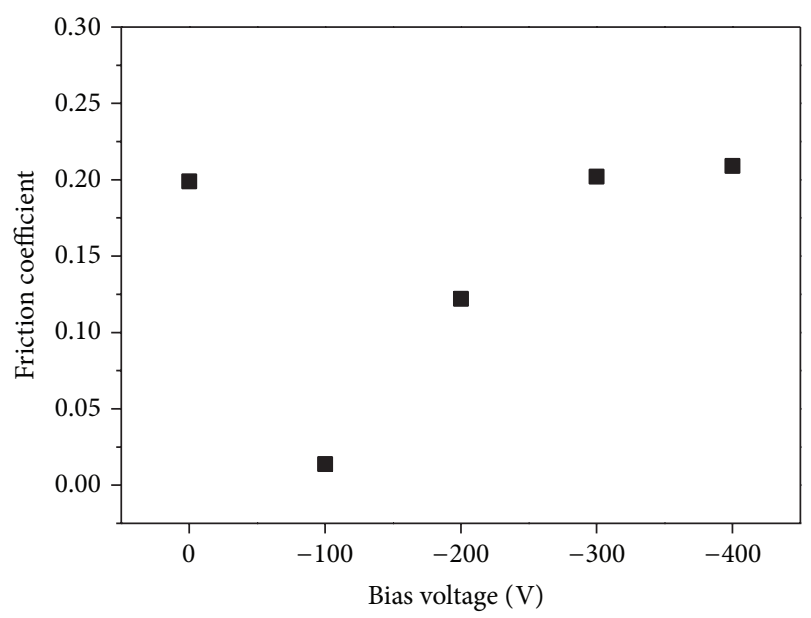

FIGURE 9: The average friction coefficient of the films as a function of the applied bias voltage.

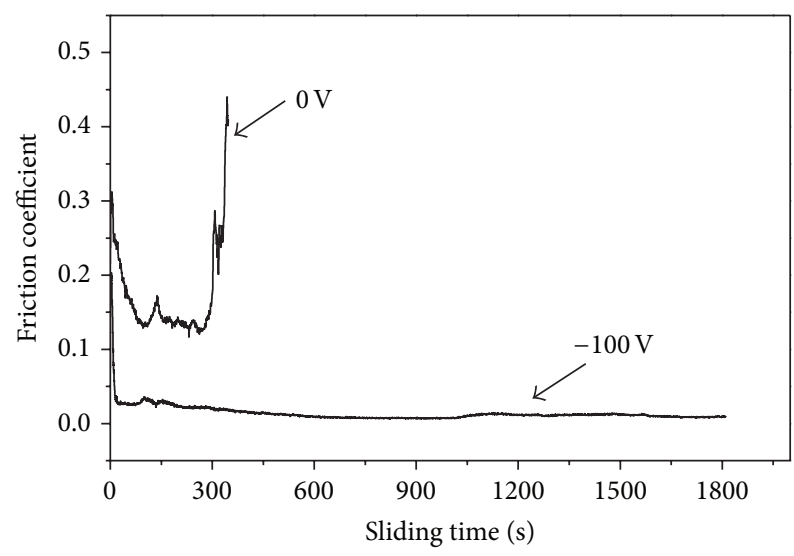

Figure 10: The dynamic friction coefficient of the films prepared at the applied bias voltage of $0 \mathrm{~V}$ and $-100 \mathrm{~V}$ as a function of sliding time. hardness. However, when the applied bias voltage was higher than $-200 \mathrm{~V}$, the dissipation of the excess heat generated by the impinging of the energetic ions could relax the high compressive stress or excess density phase that lead to loose carbon networks and more graphite-like structure in this case [23], hence resulting in a reduction of hardness. It is worth noting that the elastic modulus reached maximum value at the applied bias voltage of $-300 \mathrm{~V}$. In general, both hardness and elastic modulus of amorphous carbon films have similar variation trend with the applied bias voltage in pure or only monodoped carbon films [12, 24-26]. Therefore, it can be speculated that the hardness or modulus may be independently regulated by codoping method in a-C:H films in this study.

The $\mathrm{H} / \mathrm{E}$ and $\mathrm{H}^{3} / \mathrm{E}^{2}$ are two important parameters, which have been commonly used to describe the elastic strain to failure and resistance to the plastic deformation of the films, respectively $[27,28]$. The greater ratio of $\mathrm{H} / \mathrm{E}$ or $\mathrm{H}^{3} / \mathrm{E}^{2}$ means higher elastic and wear resistance of films. It can be seen that the $\mathrm{H} / \mathrm{E}$ and $\mathrm{H}^{3} / \mathrm{E}^{2}$ show a similar trend, which first increased and then gradually decreased with increasing the applied bias voltage, as shown in Figure 8. The film exhibits the highest $\mathrm{H} / \mathrm{E}$ and $\mathrm{H}^{3} / \mathrm{E}^{2}$ with value of 0.140 and 0.168 at the applied bias voltage of $-100 \mathrm{~V}$, although the film is the hardest at the applied bias voltage of $-200 \mathrm{~V}$. It should be mentioned that the value of $\mathrm{H} / \mathrm{E}$ reported here is considerably higher than the values of $\mathrm{H} / \mathrm{E}(0.70-0.10)$ of ta-C and a-C:H films reported in the literatures by other workers $[29,30]$.

The average friction coefficient of the films prepared at different applied bias voltage is shown in Figure 9. The average friction coefficient dramatically decreased from 0.199 to 0.0139 as the applied bias voltage increased from 0 to $-100 \mathrm{~V}$. However, the friction coefficient continuously increased to 0.209 with further increasing of the applied bias voltage. It was interesting to observe, as shown in Figure 10, that the steady-state friction coefficient of the film after a run-in stage reached an extremely low value of the order of 0.01 as the applied bias voltage was $-100 \mathrm{~V}$. Moreover, the films prepared at the applied bias voltage of $-100 \mathrm{~V}$ and $-200 \mathrm{~V}$ exhibited a good wear resistance, whereas films prepared at the applied bias voltage of $0,-300$, and $-400 \mathrm{~V}$ were seriously damaged and worn out only after sliding several hundred times. It is clear that the tribological behavior of the films can be related to $\mathrm{H} / \mathrm{E}$ or $\mathrm{H}^{3} / \mathrm{E}^{2}$ ratio. The result in this study supports the opinion often referred to in many publication literatures where the $\mathrm{H} / \mathrm{E}$ or $\mathrm{H}^{3} / \mathrm{E}^{2}$ can be a reliable indicator of wear resistance in tribological application.

\section{Conclusions}

In this paper, the Ti:Si-codoped a-C:H films were successfully prepared at different applied bias voltage by magnetron sputtering technique. The chemical composition, surface morphology, and mechanical and tribological properties of the films were investigated as a function of the applied bias voltage. The applied bias voltage plays a significant role in the evolution of surface morphology and microstructure of the films owing to changes of ion energy in the film growth. The film prepared at higher bias voltage exhibited the lower $\mathrm{sp}^{3}$ 
carbon and hydrogen fraction. There is a strong correlation between $\mathrm{H} / \mathrm{E}$ or $\mathrm{H}^{3} / \mathrm{E}^{2}$ ratio and wear performance for all the films. The film prepared at the applied bias voltage of $-100 \mathrm{~V}$ showed moderate hardness but possessed the greatest $\mathrm{H} / \mathrm{E}$ or $\mathrm{H}^{3} / \mathrm{E}^{2}$ ratio and hence demonstrated the best tribological performance, which would be a promising candidate for the applications under dry sliding conditions.

\section{Conflict of Interests}

The authors declare that there is no conflict of interests regarding the publication of this paper.

\section{Acknowledgments}

The authors gratefully acknowledge the financial support provided by the Natural Science Foundation of China (51105186), the Excellent Young Teachers Program of Lanzhou University of Technology (1010ZCX010), and the Doctoral Research grant of Lanzhou University of Technology.

\section{References}

[1] S. V. Hainsworth and N. J. Uhure, "Diamond like carbon coatings for tribology: production techniques, characterisation methods and applications," International Materials Reviews, vol. 52, no. 3, pp. 153-174, 2007.

[2] W. Tillmann, E. Vogli, and F. Hoffmann, "Wear-resistant and low-friction diamond-like-carbon (DLC)-layers for industrial tribological applications under humid conditions," Surface and Coatings Technology, vol. 204, no. 6-7, pp. 1040-1045, 2009.

[3] L. P. Wang, S. H. Wan, S. C. Wang, R. J. K. Wood, and Q. J. Xue, "Gradient DLC-based nanocomposite coatings as a solution to improve tribological performance of aluminum alloy," Tribology Letters, vol. 38, no. 2, pp. 155-160, 2010.

[4] J.-H. Ouyang, S. Sasaki, T. Murakami, Y. Zhou, and J. Zhang, "Mechanical and unlubricated tribological properties of titanium-containing diamond-like carbon coatings," Wear, vol. 266, no. 1-2, pp. 96-102, 2009.

[5] S. G. Zhou, L. P. Wang, Z. B. Lu et al., "Tailoring microstructure and phase segregation for low friction carbon-based nanocomposite coatings," Journal of Materials Chemistry, vol. 22, no. 31, pp. 15782-15792, 2012.

[6] O. Wilhelmsson, M. Ràsander, M. Carlsson et al., "Design of nanocomposite low-friction coatings," Advanced Functional Materials, vol. 17, no. 10, pp. 1611-1616, 2007.

[7] X. Q. Liu, J. Yang, J. Y. Hao, J. Y. Zheng, Q. Y. Gong, and W. M. Liu, "A near-frictionless and extremely elastic hydrogenated amorphous carbon film with self-assembled dual nanostructure," Advanced Materials, vol. 24, no. 34, pp. 4614-4617, 2012.

[8] J. L. Jiang, J. Y. Hao, X. J. Pang, P. Wang, and W. M. Liu, "Structure and characteristics of amorphous (Ti, Si)-C:H films deposited by reactive magnetron sputtering," Diamond and Related Materials, vol. 19, no. 10, pp. 1172-1177, 2010.

[9] X. Q. Liu, J. Y. Hao, J. L. Yang, J. Y. Zheng, Y. M. Liang, and W. M. Liu, "Preparation of superior lubricious amorphous carbon films co-doped by silicon and aluminum," Journal of Applied Physics, vol. 110, no. 5, Article ID 053507, 8 pages, 2011.

[10] J. L. Jiang, J. Y. Hao, P. Wang, and W. M. Liu, "Superlow friction of titanium/silicon codoped hydrogenated amorphous carbon film in the ambient air," Journal of Applied Physics, vol. 108, no. 3, Article ID 033510, 6 pages, 2010.

[11] Y. N. Kok, P. E. Hovsepian, Q. Luo, D. B. Lewis, J. G. Wen, and I. Petrov, "Influence of the bias voltage on the structure and the tribological performance of nanoscale multilayer C/Cr PVD coatings," Thin Solid Films, vol. 475, no. 1-2, pp. 219-226, 2005.

[12] W. Dai, H. Zheng, G. S. Wu, and A. Y. Wang, "Effect of bias voltage on growth property of Cr-DLC film prepared by linear ion beam deposition technique," Vacuum, vol. 85, no. 2, pp. 231$235,2010$.

[13] G. A. Zhang, P. X. Yan, P. Wang et al., "The effect of applied substrate negative bias voltage on the structure and properties of Al-containing a-C:H thin films," Surface and Coatings Technology, vol. 202, no. 12, pp. 2684-2689, 2008.

[14] X. J. Pang, L. Shi, P. Wang, Y. Q. Xia, and W. M. Liu, "Influence ofmethane flow on the microstructure and properties of TiAldoped a-C:H films deposited bymiddle frequency reactive magnetron sputtering," Surface and Interface Analysis, vol. 41, no. 12-13, pp. 924-930, 2009.

[15] P. K. Chu and L. Li, "Characterization of amorphous and nanocrystalline carbon films," Materials Chemistry and Physics, vol. 96, no. 2-3, pp. 253-277, 2006.

[16] C. Casiraghi, F. Piazza, A. C. Ferrari, D. Grambole, and J. Robertson, "Bonding in hydrogenated diamond-like carbon by Raman spectroscopy," Diamond and Related Materials, vol. 14, no. 3-7, pp. 1098-1102, 2005.

[17] C. Casiraghi, A. C. Ferrari, and J. Robertson, "Raman spectroscopy of hydrogenated amorphous carbons," Physical Review $B$, vol. 72, no. 8, Article ID 085401, 14 pages, 2005.

[18] J. Robertson, "Recombination and photoluminescence mechanism in hydrogenated amorphous carbon," Physical Review B, vol. 53, no. 24, pp. 16302-16305, 1996.

[19] J. Robertson, "Diamond-like amorphous carbon," Materials Science and Engineering, vol. 37, no. 4-6, pp. 129-281, 2002.

[20] C. Donnet and A. Erdemir, Eds., Tribology of Diamond-Like Carbon Films: Fundamentals and Applications, Springer, New York, NY, USA, 2010.

[21] X. J. Pang, J. Y. Hao, P. Wang, Y. Q. Xia, and W. M. Liu, "Effects of bias voltage on structure and properties of TiAl-doped a-C:H films prepared by magnetron sputtering," Surface and Interface Analysis, vol. 43, no. 3, pp. 677-682, 2011.

[22] P. Wang, X. Wang, Y. M. Chen, G. A. Zhang, W. M. Liu, and J. Y. Zhang, "The effect of applied negative bias voltage on the structure of Ti-doped a-C:H films deposited by FCVA," Applied Surface Science, vol. 253, no. 7, pp. 3722-3726, 2007.

[23] C. B. Wang, S. R. Yang, and J. Y. Zhang, "Ripple surface generated on hydrogenated amorphous carbon nitride films," Applied Surface Science, vol. 253, no. 8, pp. 4099-4102, 2007.

[24] W. J. Yang, T. Sekino, K. B. Shim, K. Niihara, and K. H. Auh, "Deposition and microstructure of Ti-containing diamond-like carbon nanocomposite films," Thin Solid Films, vol. 473, no. 2, pp. 252-258, 2005.

[25] H. Kim, D. H. Jung, B. Park, K. C. Yoo, J. J. Lee, and J. H. Joo, "The effect of the substrate bias voltage and the deposition pressure on the properties of diamond-like carbon produced by inductively coupled plasma assisted chemical vapor deposition," Surface and Coatings Technology, vol. 193, no. 1-3, pp. 255-258, 2005.

[26] Y. Ohtsu, H. Noda, C. Nakamura et al., "Effect of negative pulsed high-voltage-bias on diamond-like carbon thin film preparation using capacitively coupled radio-frequency plasma 
chemical vapor deposition," Surface and Coatings Technology, vol. 201, no. 15, pp. 6674-6677, 2007.

[27] S. Chowdhury, M. T. Laugier, and I. Z. Rahman, "Effect of target self-bias voltage on the mechanical properties of diamond-like carbon films deposited by RF magnetron sputtering," Thin Solid Films, vol. 468, no. 1-2, pp. 149-154, 2004.

[28] M. D. Abad, M. A. Muñoz-Márquez, S. El Mrabet, A. Justo, and J. C. Sánchez-López, "Tailored synthesis of nanostructured WC/a-C coatings by dual magnetron sputtering," Surface and Coatings Technology, vol. 204, no. 21-22, pp. 3490-3500, 2010.

[29] O. S. Panwar, I. Ishpal, R. K. Tripathi, A. K. Srivastava, M. Kumar, and S. Kumar, "Effect of substrate bias in hydrogenated amorphous carbon films having embedded nanocrystallites deposited by cathodic jet carbon arc technique," Diamond and Related Materials, vol. 25, no. 5, pp. 63-72, 2012.

[30] C. A. Charitidis, "Nanomechanical and nanotribological properties of carbon-based thin films: a review," International Journal of Refractory Metals and Hard Materials, vol. 28, no. 1, pp. 51-70, 2010. 

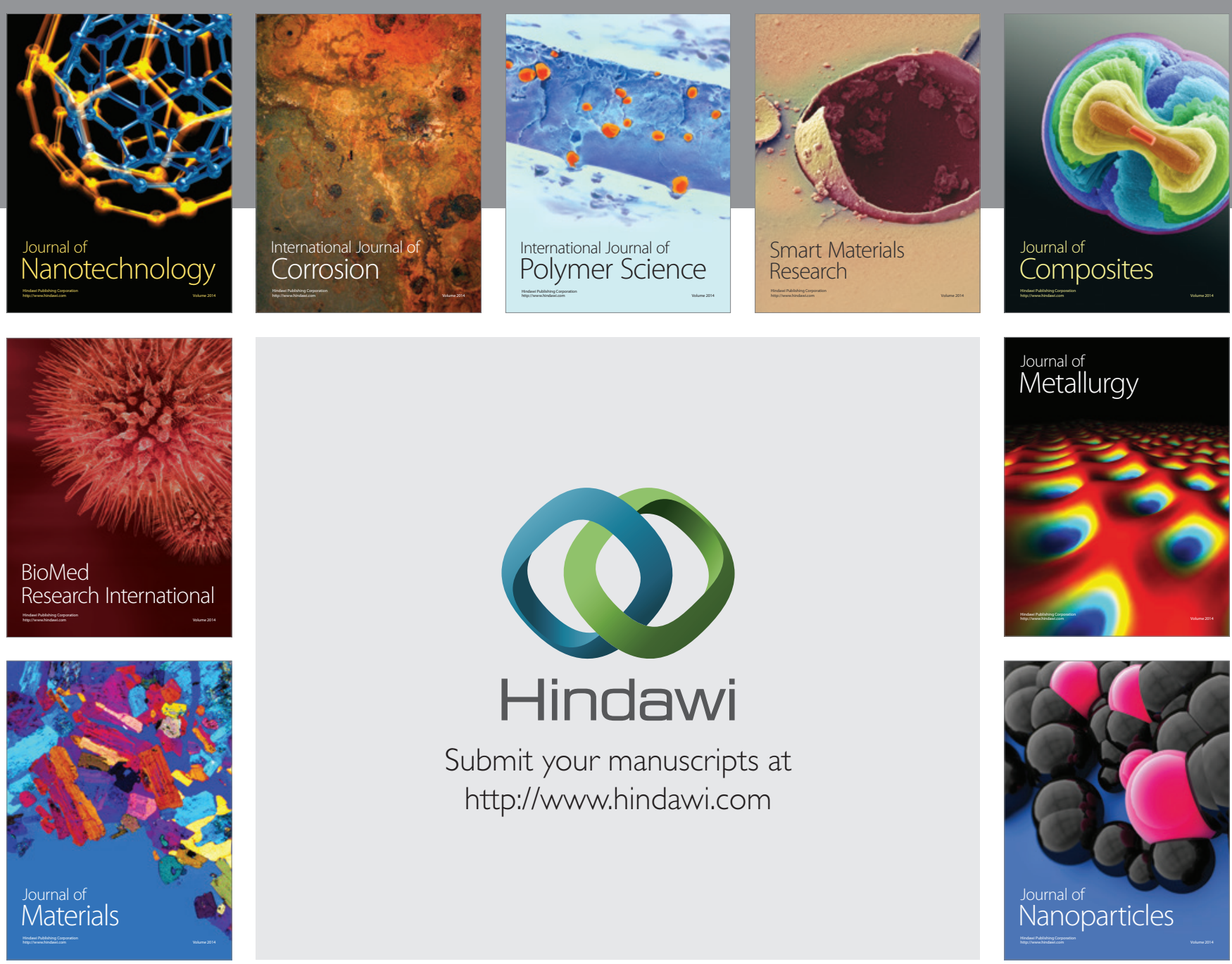

Submit your manuscripts at http://www.hindawi.com
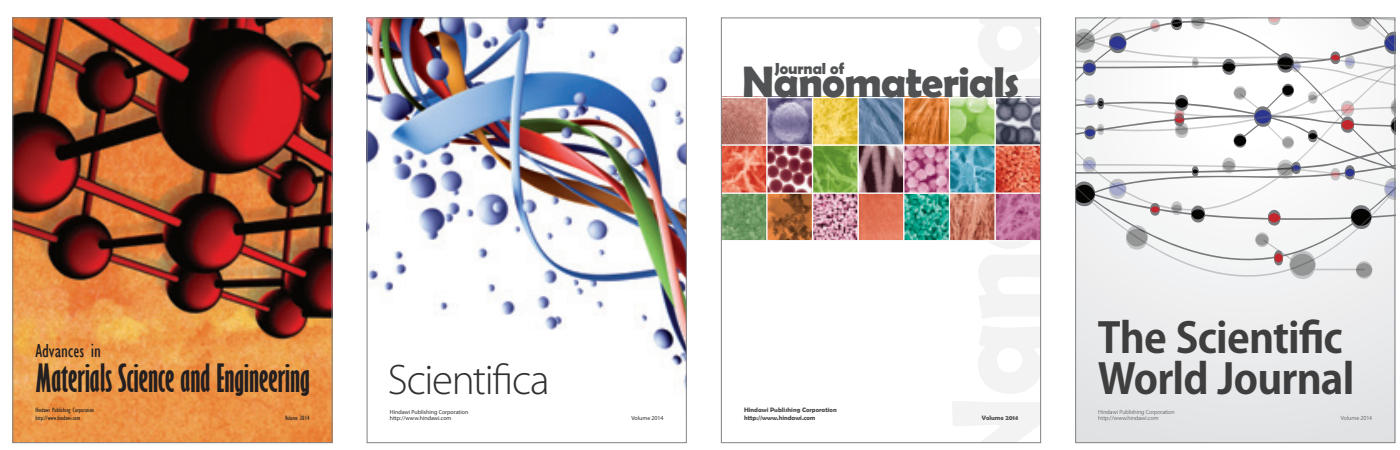

\section{The Scientific World Journal}
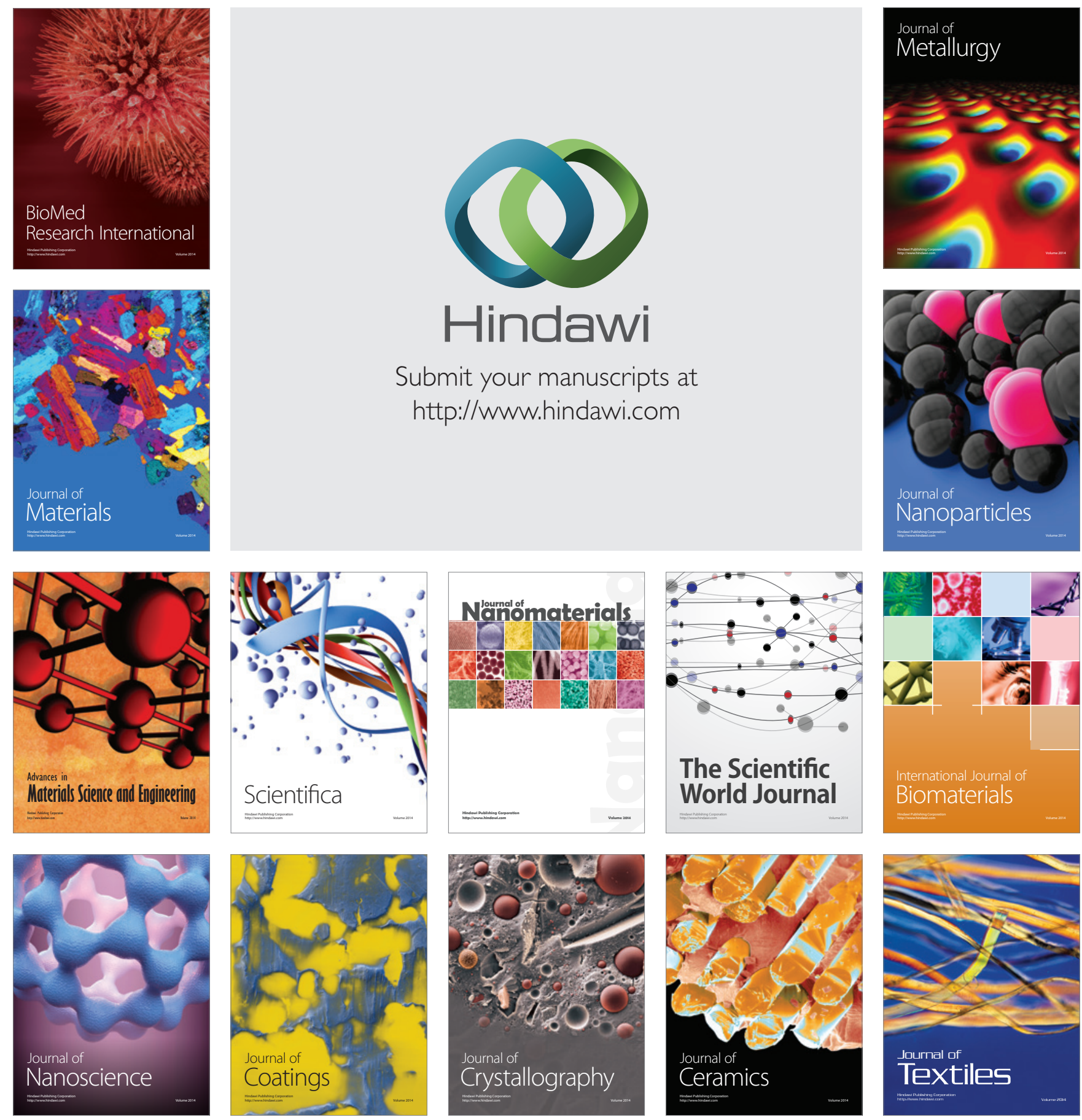